\title{
Comparison of oncological outcomes of single-port versus multi-port video-assisted thoracoscopic surgery for non-small-cell lung cancer: a propensity-matched analysis
}

\section{Dong Woog Yoon ${ }^{1}$, Yong Soo Choi ${ }^{2}$, Kiick Sung ${ }^{2}$, Hojoong Kim ${ }^{3}$}

${ }^{1}$ Department of Thoracic and Cardiovascular Surgery, Armed Forces Capital Hospital, Seongnam, Korea

${ }^{2}$ Department of Thoracic and Cardiovascular Surgery, Samsung Medical Center, Sungkyunkwan University School of Medicine, Seoul, Korea

${ }^{3}$ Division of Pulmonary and Critical Care Medicine, Department of Medicine, Samsung Medical Center, Sungkyunkwan University School of Medicine, Seoul, Korea

Received: January 27, 2020

Revised: March 5, 2020

Accepted: March 6, 2020

Corresponding author:

Yong Soo Choi

Department of Thoracic and Cardiovascular Surgery, Samsung Medical Center, Sungkyunkwan University School of Medicine, 81 Irwonro, Gangnam-gu, Seoul 06351, Korea

Tel: $+82-2-3410-6542$

E-mail: choi.smcts@gmail.com

This is an Open Access article distributed under the terms of the Creative Commons Attribution Non-Commercial License (https:// creativecommons.org/licenses/ by-nc/4.0/).

\section{ABSTRACT}

Purpose: There are few reports about oncological outcomes of single-port (SP) video-assisted thoracoscopic surgery (VATS) lobectomy, represented by overall survival (OS), disease-free survival (DFS), and adequacy of lymph node retrieval. We designed this study to analyze the oncological outcomes of SP versus multi-port (MP) VATS lobectomy for non-small-cell lung cancer (NSCLC).

Methods: From January 2012 to February 2014, 243 consecutive patients undergoing VATS lobectomy for NSCLC were enrolled. Intention-to-treat analysis with propensity score matching was conducted to compare the oncological outcomes between SP and MP VATS lobectomy for NSCLC.

Results: Seventy-three patients underwent SP VATS lobectomy, and 154 patients underwent conventional MP VATS lobectomy. Propensity score matching created $63 \mathrm{pa}-$ tients in each group. The median follow-up was 65.8 and 72.5 months in the SP and MP VATS groups, respectively. No significant differences were observed in the number of resected lymph nodes (14.6 vs. 16.1, $\mathrm{P}=0.329)$, number of resected mediastinal lymph node stations ( 2.3 vs. $2.5, P=0.091$ ), and postoperative complications. The OS at 5 years was $89.9 \%$ and $86.9 \%$ in the SP and MP VATS groups, respectively (log-rank test, $P=0.344$ ). The DFS at 5 years was $75.1 \%$ and $75.7 \%$ in the SP and MP VATS groups, respectively (log-rank test, $\mathrm{P}=0.899$ ).

Conclusion: There were no significant differences in oncological outcomes of SP VATS lobectomy for NSCLC and those of MP VATS lobectomy.

Keywords: Carcinoma, non-small-cell lung; Survival rate; Thoracic surgery, video-assisted 


\section{INTRODUCTION}

Lung cancer is the most common cancers in the world and its prevalence is increasing. In Korea, there are 25,780 annual incident cases of lung cancer [1]. For the intent of cure, anatomical resection remains the gold standard of lung cancer therapy. Video-assisted thoracoscopic surgery (VATS) in selected patients results in improved perioperative outcomes without compromising the cancer outcomes [2-9]. Recently, the existing VATS technique has been further developed, and single-port (SP) VATS lobectomy has been performed with a single incision [10]. SP VATS has resulted in shorter hospital stay [11], less intraoperative blood loss [12], and decreased pain $[13,14]$, although not all studies have shown the same results [15]. However, there are few reports about oncological outcomes of SP VATS lobectomy. Previous studies reported acceptable survival outcomes but showed only 1- or 2-year survival outcomes [16-18]. The objective of this research was to compare the oncological outcomes, including long-term overall survival (OS), disease-free survival (DFS), and adequacy of lymph node retrieval, in two comparable propensity-matched groups of patients undergoing either SP or multi-port (MP) VATS lobectomy for non-small-cell lung cancer (NSCLC).

\section{METHODS}

\section{Study design and patient selection}

We retrospectively reviewed lung cancer data at the Sam- sung Medical Center. The following tests were involved in a staging workup: a complete history and physical examination, complete blood counts, chemistry profiles, pulmonary function tests, simple chest X-ray, computed tomography of the chest and upper abdomen, whole-body ${ }^{18 F}$-fluorodeoxyglucose positron emission tomography, and magnetic resonance imaging of the brain. A curative-intent anatomical resection was recommended to the patients with clinical stage I or II. In cases of stage IIIA patients, we generally recommended definitive concurrent chemoradiotherapy (CCRT) if cancer lesions were unresectable. When tumors were considered resectable, we conducted neoadjuvant CCRT, and performed surgical resection after 4 to 6 weeks from the completion of CCRT.

To be included in this study, patients needed to undergo curative-intent surgical lobectomy for NSCLC. The data of all patients $(n=243)$ undergoing lobectomy performed by an author (YSC) between January 2012 and February 2014 at the Samsung Medical Center in Seoul, Korea, were reviewed. We excluded 16 patients for the following reasons: surgery started with thoracotomy (14 patients), loss to follow-up after surgery (one patient), and no pulmonary function test before surgery (one patient). After exclusion, 227 patients were enrolled in this study.

SP VATS was introduced in June 2012 and was initially only performed in wedge resection of lung cancer or lobectomy for benign lung diseases. After the surgeons have been accustomed to the new surgical approach, SP VATS lobectomy

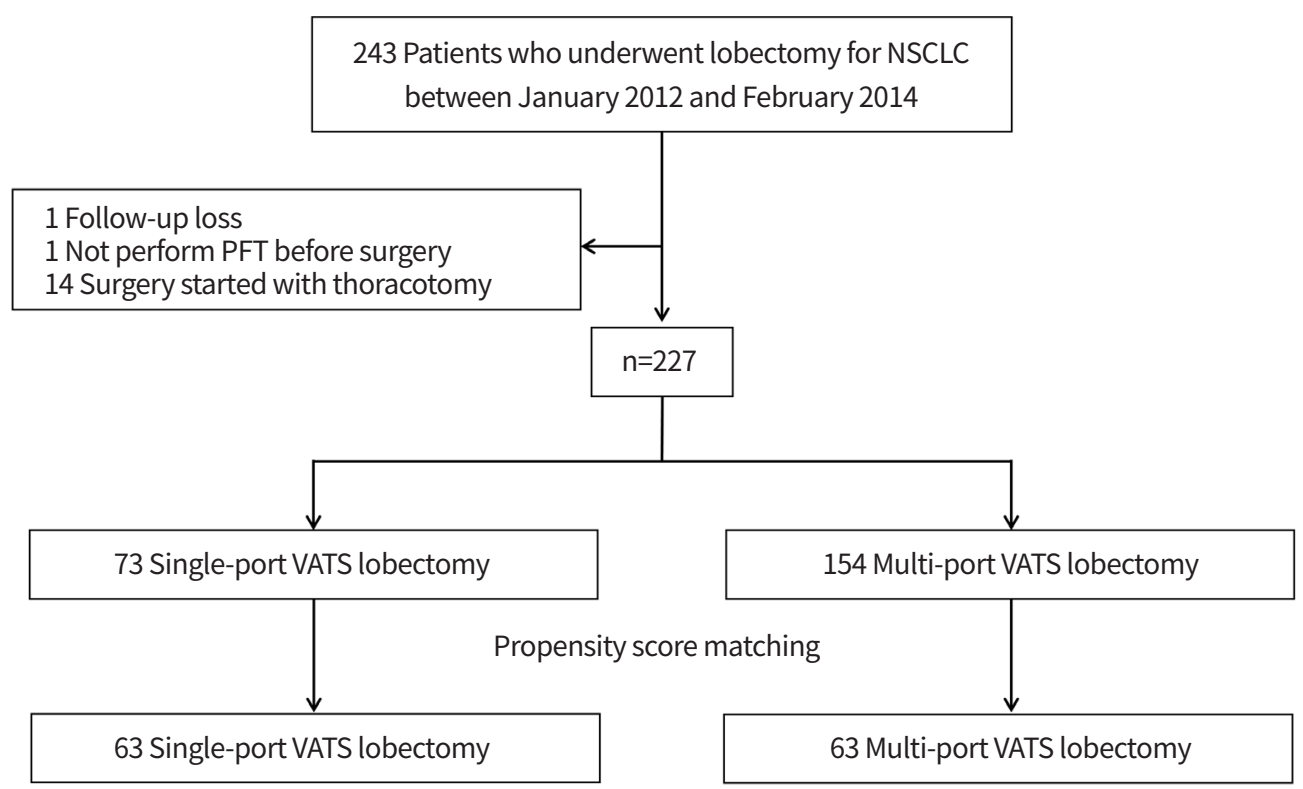

Fig. 1. Flowchart summarizing the patient selection and propensity score matching processes. NSCLC, non-small-cell lung cancer; PFT, pulmonary function test; VATS, video-assisted thoracoscopic surgery. 
for NSCLC started in May 2013. From May 2013, we have chosen the SP VATS technique in all lung cancer patients except for central tumor or sizes greater than five centimeters.

To minimize selection bias and evaluate the real impact of SP VATS, we conducted an intention-to-treat analysis. The SP VATS group included patients who initially underwent SP VATS but were converted to MP VATS or open surgery owing to intraoperative circumstances. The SP VATS lobectomy group comprised 73 patients, and the MP VATS lobectomy group consisted of 154 patients. Propensity score matching yielded 63 patients in each group, and we compared the oncological outcomes of SP VATS with those of MP VATS (Fig. 1).

The study was approved by the Institutional Review Board (IRB) of the Samsung Medical Center; the requirement for informed consent was waived (IRB no. SMC 2017-07-055-003).

\section{Surgical technique}

All patients received general anesthesia with double-lumen intubation and were placed in the lateral decubitus position. The operator stood on the right side of the patient, and two assistants stood on the left side. The assistant rotated the camera $90^{\circ}$ towards the operator, giving the assistants on the left side the same view as during an open thoracotomy. The operator watched another monitor rotated $180^{\circ}$ to perform the surgery, also with the same view as during open thoracotomy. And the same surgical instruments were used for the SP and MP VATS.

The same surgical instruments were used for SP VATS and MP VATS. SP VATS was mostly started with a mid-axillary 5-mm incision at the 5th intercostal space (ICS). In case of upper lobe procedure, 4th ICS incision was used in some cases, and 6th ICS in case of lower lobe procedure. After the first checking of the pleural space through this incision with a $5-\mathrm{mm} 30^{\circ}$ thoracoscope, the 5-mm incision was enlarged to a 3.5 to $5 \mathrm{~cm}$ at the mid-axillary line (Supplementary Fig. $1 \mathrm{~A}$ ).

A same size incision at the same location was created in the conventional MP VATS, and used as a utility port. Two 5and 12-mm incisions at the mid-axillary line at the 4th and 7th ICS were added for ports in the conventional MP VATS Iobectomy procedure (Supplementary Fig. 1B).

Radical mediastinal lymph node resection was routinely conducted in the same manner in both groups. When the procedure was finished, a single chest tube was inserted into the anterior part of the incision for SP VATS and into the port at the 7 th ICS for conventional MP VATS.

\section{Data acquirement and follow-up}

All patients visited the outpatient clinic 1 week after discharge, then every 3 months for the first 2 years and every 6 months thereafter. Survival data were renewed in March 2019 according to the medical records of the Samsung Medical Center or by directly contacting the patients. Recurrence of lung cancer was defined as loco-regional if cancer recurred in the ipsilateral thorax (mediastinum, hilum, and pleura) or at the surgical margin. Distant recurrence was determined when cancer developed in the contralateral thorax (lung, mediastinum, hilum, and pleura), ipsilateral lung, supraclavicular lymph node, or a distant organ. A recurrence simultaneously detected in both a local area and a distant area was defined as a local recurrence. We used the TNM (tumor, node, metastasis) stage of the American Joint Committee on Cancer staging system, 7th edition. After matched analysis, the median follow-up time of the SP and MP VATS patients was 65.8 and 72.5 months, respectively.

\section{Statistical analysis}

We used a 1:1 matching analysis between the SP and MP VATS lobectomy groups according to the propensity scores. From this, we can minimize selection bias which can caused by the nonrandom distribution of patients to the treatment groups. Propensity scores were created by a logistic regression model including the variables: age, sex, Charlson comorbidity index, smoking history, American Society of Anesthesiologists Risk Scale, forced expiratory volume in 1 second $\left(\mathrm{FEV}_{1}\right), \mathrm{FEV}_{1} /$ forced vital capacity ratio, histology, clinical tumor $(\mathrm{T})$ and nodal (N) status, and previous chemotherapy or radiotherapy. Each patient undergoing SP VATS lobectomy was matched with a patient undergoing MP VATS lobectomy based on the closest calculated propensity score on the logit scale.

Continuous data were presented as mean \pm SD. Categorical variables were presented as frequency and percentages. Differences among the groups were examined using 2-way analysis of variance for both continuous and categorical variables. Survival data was created using the Kaplan-Meier method.

\section{RESULTS}

\section{Patients characteristics}

After propensity score matching with 12 variables, 63 patients from each group were paired, and clinical stage I accounted for $87.3 \%$ of the SP VATS group and $80.9 \%$ of the MP VATS group. Table 1 showed characteristics of all patients. 
PRECISION AND FUTURE MEDICINE

Dong Woog Yoon, et al.

Table 1. Patients' characteristics

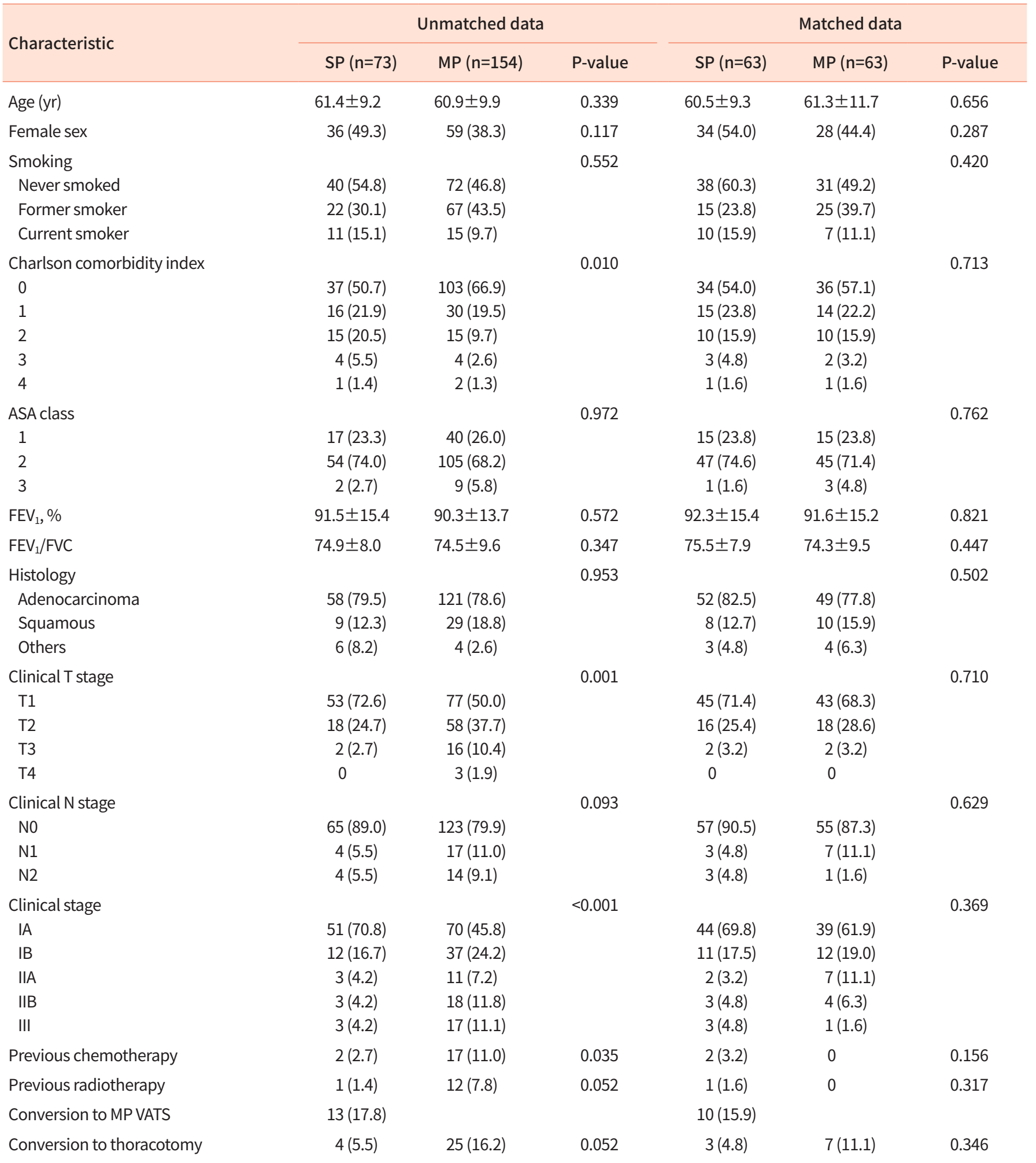

Values are presented as mean \pm standard deviation or number (\%).

SP, single-port; MP, multi-port; ASA, American Society of Anesthesiologists; FEV ${ }_{1}$, forced expiratory volume in 1 second; FVC, forced vital capacity; VATS, video-assisted thoracoscopic surgery. 


\section{PRECISION AND FUTURE MIEDICINE \\ Oncological outcomes of single-port VATS}

To examine the representativeness of the selected patients, we compared the difference in variables before and after matching in each group. The details are provided in Supplementary Table 1.

A conversion from SP VATS to MP VATS and thoracotomy was performed in 13 and four patients, respectively. Further,

Table 2. Reasons for conversion

\begin{tabular}{llc}
\hline Surgical approach & \multicolumn{1}{c}{$\begin{array}{c}\text { Reason for } \\
\text { conversion }\end{array}$} & Number \\
\hline $\begin{array}{l}\text { From single-port to } \\
\text { multi-port }\end{array}$ & $\begin{array}{l}\text { Anthracofibrosis } \\
\text { Extranodal invasion }\end{array}$ & 3 \\
& Severe adhesion & 4 \\
& Anatomical difficulty & 4 \\
From single-port to & Severe adhesion & 3 \\
thoracotomy & Extranodal invasion & 1 \\
From multi-port to & Anthracofibrosis & 4 \\
thoracotomy & Severe adhesion & 12 \\
& Large tumor size & 1 \\
& Incomplete fissure & 4 \\
& Rib invasion & 1 \\
& Intraoperative bleeding & 2 \\
& Miscellaneous & 1 \\
\hline
\end{tabular}

a conversion from MP VATS to thoracotomy was conducted in 25 patients. The cause of conversion are listed in Table 2.

\section{Pathological findings}

After matched analysis, there are no differences between two groups in the total number of resected lymph nodes (14.6 vs. 16.1, $P=0.329$ ) and the number of resected mediastinal lymph node stations ( 2.3 vs. $2.5, P=0.091$ ). There were also no differences in pathological stage and pattern of nodal upstaging. The details of pathological findings are shown in Table 3.

\section{Perioperative outcomes}

In the MP VATS group, one patient died of acute respiratory distress syndrome at 17 days after surgery. After matched analysis, no in-hospital death or 90-day mortality was observed in either group. There was no difference between the groups in the length of hospital stay (6.4 days vs. 6.6 days, $P=0.121$ ). The operative time was longer in the MPVATS group (142 minutes vs. 165 minutes, $P=0.020$ ). Table 4 showed the details of perioperative outcomes.

The SP VATS group had eight cases of complications, and the MP VATS group had 14 cases of complications. In the

Table 3. Pathological findings

\begin{tabular}{|c|c|c|c|c|c|c|}
\hline \multirow{2}{*}{ Variable } & \multicolumn{3}{|c|}{ Unmatched data } & \multicolumn{3}{|c|}{ Matched data } \\
\hline & $\operatorname{SP}(n=73)$ & $M P(n=154)$ & P-value & $S P(n=63)$ & $M P(n=63)$ & P-value \\
\hline Pathological stage & & & 0.687 & & & 0.934 \\
\hline la & $38(52.1)$ & $72(46.7)$ & & $34(54)$ & $33(52.4)$ & \\
\hline $\mathrm{lb}$ & $11(15.1)$ & $33(21.4)$ & & $10(15.9)$ & $15(23.8)$ & \\
\hline Ila & $8(11.0)$ & $12(7.8)$ & & $8(12.7)$ & $3(4.8)$ & \\
\hline Ilb & $2(2.7)$ & $12(7.8)$ & & $1(1.6)$ & $4(6.3)$ & \\
\hline Illa & $13(17.8)$ & $22(14.3)$ & & $10(15.9)$ & $7(11.1)$ & \\
\hline IV & $1(0.6)$ & $1(0.6)$ & & 0 & 0 & \\
\hline Complete remission & 0 & $2(1.3)$ & & 0 & $1(0.8)$ & \\
\hline Resected N1 LNs & $7.0 \pm 4.6$ & $8.1 \pm 5.1$ & 0.116 & $6.9 \pm 4.6$ & $7.8 \pm 5.3$ & 0.336 \\
\hline Resected N2 LNs & $7.5 \pm 4.1$ & $8.6 \pm 6.6$ & 0.136 & $7.7 \pm 4.1$ & $8.3 \pm 6.5$ & 0.533 \\
\hline Total resected LNs & $14.5 \pm 6.9$ & $16.6 \pm 9.1$ & 0.053 & $14.6 \pm 6.9$ & $16.1 \pm 9.4$ & 0.329 \\
\hline Resected N2 stations & $2.3 \pm 0.8$ & $2.8 \pm 1.3$ & 0.001 & $2.3 \pm 0.8$ & $2.5 \pm 1.0$ & 0.091 \\
\hline Nodal upstaging & $18(24.7)$ & $19(12.3)$ & 0.021 & $15(23.8)$ & $9(14.3)$ & 0.206 \\
\hline $\mathrm{cNO} \rightarrow \mathrm{pN} 1$ & $7(9.6)$ & $7(4.5)$ & & $7(11.1)$ & $2(3.2)$ & \\
\hline $\mathrm{cNO} \rightarrow \mathrm{pN} 2$ & $8(11.0)$ & $9(5.8)$ & & $6(9.5)$ & $4(6.3)$ & \\
\hline $\mathrm{cN} 1 \rightarrow \mathrm{pN} 2$ & $3(4.1)$ & $3(1.9)$ & & $2(3.2)$ & $3(4.8)$ & \\
\hline
\end{tabular}

Values are presented as number (\%) or mean \pm standard deviation.

$\mathrm{SP}$, single-port; MP, multi-port; LN, lymph node. 
analysis with respect to the Clavien-Dindo classification [19], the severity of surgical complications did not show any differences between the two groups. Supplementary Table 2 showed the details of postoperative complications.

\section{Overall survival}

The 5-year OS was $89.9 \%$ in the SP VATS group and $86.9 \%$ in the MP VATS group (log-rank test, $P=0.339$ ) (Fig. 2A). The surgical approach for SP VATS was not a significant predictor of
OS (hazard ratio [HR], 0.61; 95\% confidence interval [Cl], 0.22 to $1.69 ; \mathrm{P}=0.344$ ) in univariate analysis. The 5 -year OS for clinical stage I NSCLC was $90.4 \%$ in the SP VATS group and $89.9 \%$ in the MP VATS group (log-rank test, $P=0.947$ ) (Fig. 2C).

\section{Disease-free survival and recurrence pattern}

After matched analysis, 16 patients $(25.4 \%)$ in the SP VATS group and 13 patients $(20.6 \%)$ in the MP VATS group had a recurrence. There was no difference between the groups in the

Table 4. Perioperative findings

\begin{tabular}{|c|c|c|c|c|c|c|}
\hline \multirow{2}{*}{ Variable } & \multicolumn{3}{|c|}{ Unmatched data } & \multicolumn{3}{|c|}{ Matched data } \\
\hline & $S P(n=73)$ & $M P(n=154)$ & P-value & $\operatorname{SP}(n=63)$ & $M P(n=63)$ & P-value \\
\hline Operative time (min) & $146(123-187)$ & $165(135-210.8)$ & 0.028 & $142(121-177)$ & $165(135-213)$ & 0.020 \\
\hline Blood loss (mL) & $200(100-200)$ & $150(100-300)$ & 0.354 & $200(100-200)$ & $200(100-300)$ & 0.108 \\
\hline Length of hospital stay (day) & $6.5(4.6-8.5)$ & $7.00(5.5-10.5)$ & 0.019 & $6.4(4.5-7.6)$ & $6.6(5.0-10.0)$ & 0.121 \\
\hline In-hospital death & 0 & 1 & & 0 & 0 & \\
\hline 90-Day mortality & 0 & 1 & & 0 & 0 & \\
\hline
\end{tabular}

Values are presented as median (interquartile range).

$\mathrm{SP}$, single-port; MP, multi-port.

Overall survival (matched analysis)

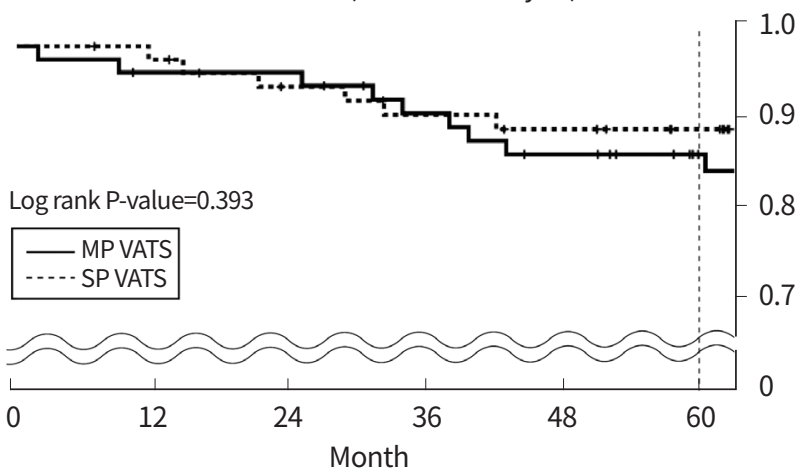

Overall survival (matched analysis, Stage I)

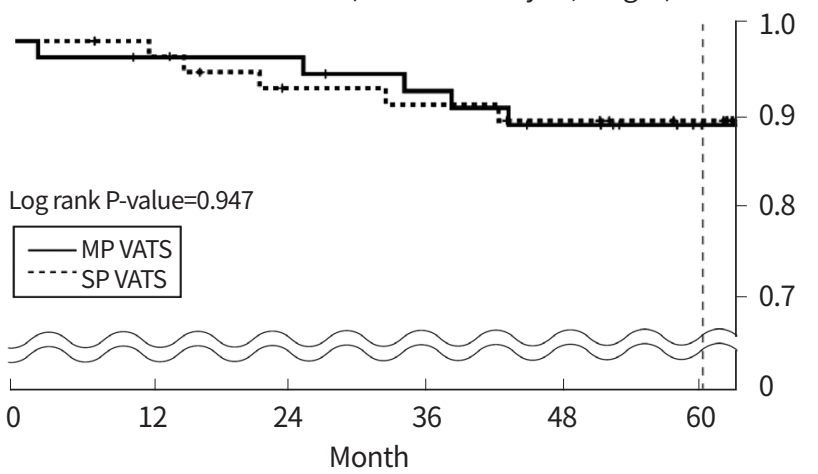

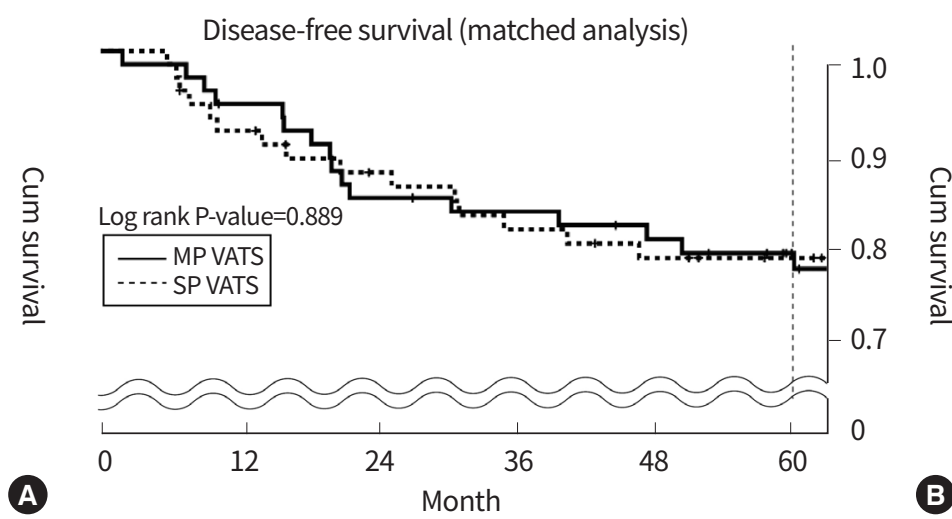

Disease-free survival (matched analysis, Stage I)

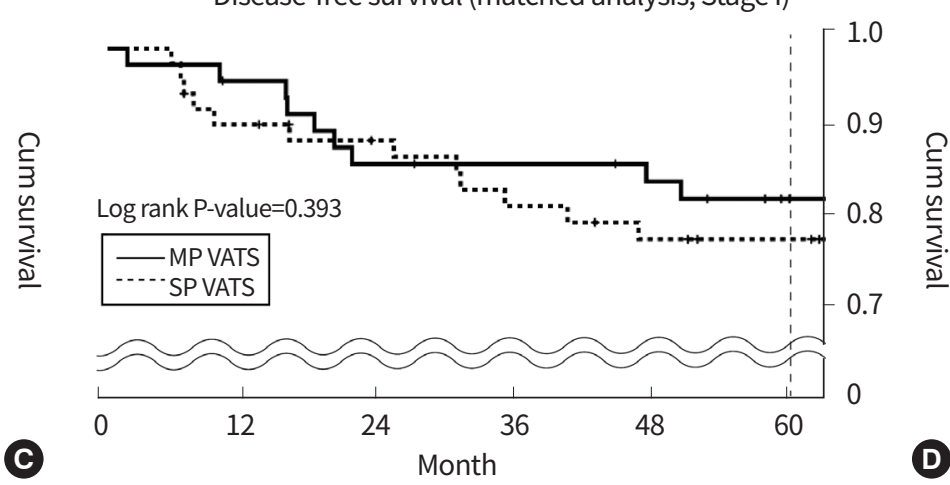

Fig. 2. Survival analysis of single-port (SP) video-assisted thoracic surgery (VATS) versus multi-port (MP) VATS: (A) overall survival of the matched group, (B) disease-free survival of the matched group, (C) overall survival of stage I patients of the matched group, and (D) disease-free survival of stage I patients of the matched group. 
Table 5. Recurrence patterns

\begin{tabular}{|c|c|c|c|c|c|c|}
\hline \multirow{2}{*}{ Variable } & \multicolumn{3}{|c|}{ Unmatched data } & \multicolumn{3}{|c|}{ Matched data } \\
\hline & $S P(n=73)$ & $M P(n=154)$ & P-value & $S P(n=63)$ & $M P(n=63)$ & P-value \\
\hline Recurrence & $19(26.0)$ & $52(33.8)$ & 0.241 & $16(25.4)$ & $13(20.6)$ & 0.527 \\
\hline Pattern of recurrence & & & 0.272 & & & 0.398 \\
\hline Loco-regional ( \pm distant) & $8(11.0)$ & $24(15.6)$ & & $6(9.5)$ & $9(14.3)$ & \\
\hline Distant only & $11(15.1)$ & $28(18.2)$ & & $10(15.9)$ & $4(6.3)$ & \\
\hline
\end{tabular}

Values are presented as number (\%).

$\mathrm{SP}$, single-port; MP, multi-port.

location of recurrence (Table 5). The 5-year DFS was $75.1 \%$ in the SP VATS group and $75.7 \%$ in the MP VATS group (log-rank test, $\mathrm{P}=0.899$ ) (Fig. 2B). The surgical approach for SP VATS was not a significant predictor of DFS (HR, 1.05; 95\% Cl, 0.52 to $2.09 ; \mathrm{P}=0.899$ ) in univariate analysis. The 5 -year $\mathrm{DFS}$ for clinical stage I NSCLC was $77.0 \%$ in the SP VATS group and $81.9 \%$ in the MP VATS group (log-rank test, $P=0.393$ ) (Fig. 2D).

\section{DISCUSSION}

In recent years, SP VATS has been considered to be an achievable, minimally invasive procedure that is comparable to conventional MP VATS in terms of perioperative outcomes [11-15]. And these studies reported significantly lower pain scores of patients undergoing SP VATS compared to those of MP VATS $[13,14]$. In the current study, the SP VATS group was found to have similar OS, DFS, recurrence pattern, lymph node retrieval, nodal upstaging, and complications to the MP VATS group.

The primary finding of no difference in OS and DFS between SP VATS and MP VATS for NSCLC is important because the current study is the first to report the 5-year oncological outcomes in patients undergoing SP VATS lobectomy for the treatment of NSCLC. The 5-year OS and DFS in the clinical stage I SP VATS group compared favorably with those in reports of long-term outcomes [5-7,9]. The investigation of the prevalence and distribution of recurrence also did not bring in any difference between the two different operative technique. On the basis of these data, our study demonstrated that the long-term oncological outcomes of the SP VATS technique are at least equivalent to those of conventional MPVATS.

There is a concern that because of technical difficulty, the SP VATS technique compromises the oncological principle of complete surgical lymph node dissection [20]. With this com- pleteness of lymph node dissection, clinically occult metastases can be found and patients can be treated appropriately. Previous studies demonstrated that fewer resected lymph nodes led to worse survival and that the survival rates were better in patients in whom $>11$ lymph nodes were resected [21-24]. To evaluate the adequacy of lymph node dissection during SP VATS, we compared the number of resected lymph nodes, number of resected N2 lymph node stations, and nodal upstaging between the two groups. Liu et al. [11] and Wang et al. [12] reported a larger number of resected lymph nodes with SP VATS than with MP VATS. However, in the current study, the number of resected lymph nodes did not differ between the groups, supporting the claim that SP VATS is not inferior to conventional MP VATS in achieving complete lymph node dissection. The number of resected mediastinal lymph node stations was significantly different between the two groups before matched analysis; however, this difference disappeared after the matched analysis. The difference in the pre-matching analysis may be due to the more aggressive lymph node dissections in patients with advanced-stage NSCLC. Reports that question the oncological efficacy of VATS for NSCLC also noted that the rate of nodal upstaging after VATS was lower than after open lobectomy [25-27]. In the same way, we evaluated the nodal upstaging and could not find significant differences between the two groups in all types of nodal upstaging, including upstaging from clinical N0 to pathological N1 or N2. This also suggests that lymph node dissection during SP VATS is not inferior to that during MP VATS.

In our study, conversion to MP VATS was conducted in about $15 \%$ of the SP VATS group. When difficult circumstances were encountered during surgery, we added additional ports. Adding a port with a new angle helped with fine dissection in an area that was not easily accessible with SP VATS. When the operation was difficult even after adding 
new ports, we converted to thoracotomy. We cannot find significant difference in the conversion rate between the two groups.

With respect to postoperative complications, our results are in line with those of previous studies. Two studies from Taiwan $[11,12]$ reported similar complication rates between the SP and MP VATS groups, and other studies from Japan [14] and China [13,15] also showed the same results. These findings suggested that the SP VATS technique would not increase the complication rate if the surgeons are already accustomed to this technique.

There are several limitations in this study. First, this study was based on retrospective data from medical records. Unobserved confounding factors and selection bias may exist despite the use of propensity score matching. Second, the number of patients in each group was insufficient to discuss the oncological outcomes of a particular surgical approach. Third, selection bias could not be avoided despite performing propensity score matching. Patients with a central tumor or a tumor $>5 \mathrm{~cm}$ in size underwent MP VATS lobectomy, and the selected patients in the MP VATS group consisted of those who had lower clinical T stage and did not receive previous chemotherapy or radiotherapy compared with the entire MP VATS group. Fourth, all surgeries were conducted by a single surgeon at a single institution, making our patient population homogeneous.

In conclusion, after propensity score matching, there are no significant differences in OS and DFS between SP VATS and MP VATS lobectomy for the treatment of NSCLC. Moreover, we found no difference in the completeness of lymph node dissection, as evidenced by the number of resected nodes, number of resected N2 lymph node stations, and rate of nodal upstaging in the two groups. From these results, we can conclude that SP VATS lobectomy for NSCLC is safe and can achieve oncological outcomes similar to those of conventional MP VATS lobectomy. Therefore, for experienced surgeon, we recommend to conduct SP VATS which has advantage of reduced postoperative pain $[13,14]$. Further studies comparing the benefits and specific indications of SP VATS lobectomy are warranted.

\section{CONFLICTS OF INTEREST}

No potential conflict of interest relevant to this article was reported.

\section{ORCID}

Dong Woog Yoon https://orcid.org/0000-0003-3845-9151

Yong Soo Choi https://orcid.org/0000-0002-2552-0067

Kiick Sung https://orcid.org/0000-0003-0768-9587

Hojooing Kim https://orcid.org/0000-0001-9207-0433

\section{AUTHOR CONTRIBUTIONS}

Conception or design: DWY, YSC, KS, HK.

Acquisition, analysis, or interpretation of data: DWY, YSC, KS, HK.

Drafting the work or revising: DWY, YSC.

Final approval of the manuscript: DWY, YSC, KS, HK.

\section{REFERENCES}

1. Korean Statistical Information Service. Number of cancer incidence by 24 cancer species/gender/age ( 5 years), incidence rate [Internet]. Daejeon (KR): KOSIS; 2020 [cited 2020 Mar 6]. Available from: http://kosis.kr/statHtml/statHtml. do?orgld=117\&tblld=DT_117N_A00023\&conn_path=I2.

2. Swanson SJ, Herndon JE 2nd, D’Amico TA, Demmy TL, McKenna RJ Jr, Green MR, et al. Video-assisted thoracic surgery lobectomy: report of CALGB 39802. A prospective, multi-institution feasibility study. J Clin Oncol 2007; 25:4993-7.

3. Scott WJ, Allen MS, Darling G, Meyers B, Decker PA, Putnam JB, et al. Video-assisted thoracic surgery versus open lobectomy for lung cancer: a secondary analysis of data from the American College of Surgeons Oncology Group Z0030 randomized clinical trial. J Thorac Cardiovasc Surg 2010;139:976-81.

4. Paul S, Altorki NK, Sheng S, Lee PC, Harpole DH, Onaitis MW, et al. Thoracoscopic lobectomy is associated with lower morbidity than open lobectomy: a propensitymatched analysis from the STS database. J Thorac Cardiovasc Surg 2010;139:366-78.

5. Su S, Scott WJ, Allen MS, Darling GE, Decker PA, McKenna RJ, et al. Patterns of survival and recurrence after surgical treatment of early stage non-small cell lung carcinoma in the ACOSOG Z0030 (ALLIANCE) trial. J Thorac Cardiovasc Surg 2014;147:747-52.

6. Lee PC, Nasar A, Port JL, Paul S, Stiles B, Chiu YL, et al. Long-term survival after lobectomy for non-small cell lung cancer by video- assisted thoracic surgery versus thoracotomy. Ann Thorac Surg 2013;96:951-60. 
7. Yang CJ, Kumar A, Klapper JA, Hartwig MG, Tong BC, Harpole $\mathrm{DH} \mathrm{Jr}$, et al. A national analysis of long-term survival following thoracoscopic versus open lobectomy for stage I non-small-cell lung cancer. Ann Surg 2019;269:163-71.

8. Nwogu CE, D'Cunha J, Pang H, Gu L, Wang X, Richards WG, et al. VATS lobectomy has better perioperative outcomes than open lobectomy: CALGB 31001, an ancillary analysis of CALGB 140202 (Alliance). Ann Thorac Surg 2015;99:399405.

9. Stephens N, Rice D, Correa A, Hoffstetter W, Mehran R, Roth J, et al. Thoracoscopic lobectomy is associated with improved short-term and equivalent oncological outcomes compared with open lobectomy for clinical Stage I non-small-cell lung cancer: a propensity-matched analysis of 963 cases. Eur J Cardiothorac Surg 2014;46:607-13.

10. Gonzalez-Rivas D, Paradela M, Fernandez R, Delgado M, Fieira E, Mendez L, et al. Uniportal video-assisted thoracoscopic lobectomy: two years of experience. Ann Thorac Surg 2013;95:426-32.

11. Liu CC, Shih CS, Pennarun N, Cheng CT. Transition from a multiport technique to a single-port technique for lung cancer surgery: is lymph node dissection inferior using the single-port technique? Eur J Cardiothorac Surg 2016; 49 Suppl 1:i64-72.

12. Wang BY, Liu CY, Hsu PK, Shih CS, Liu CC. Single-incision versus multiple- incision thoracoscopic lobectomy and segmentectomy: a propensity-matched analysis. Ann Surg 2015;261:793-9.

13. Wang L, Liu D, Lu J, Zhang S, Yang X. The feasibility and advantage of uniportal video-assisted thoracoscopic surgery (VATS) in pulmonary lobectomy. BMC Cancer 2017; 17:75.

14. Hirai K, Takeuchi S, Usuda J. Single-incision thoracoscopic surgery and conventional video-assisted thoracoscopic surgery: a retrospective comparative study of perioperative clinical outcomes. Eur J Cardiothorac Surg 2016;49 Suppl 1:i37-41.

15. Shen Y, Wang H, Feng M, Xi Y, Tan L, Wang Q. Single- versus multiple-port thoracoscopic lobectomy for lung cancer: a propensity-matched study. Eur J Cardiothorac Surg 2016; 49 Suppl 1:i48-53.

16. Wu CF, Fernandez R, de la Torre M, Delgado M, Fieira E, Wu CY, et al. Mid-term survival outcome of single-port video-assisted thoracoscopic anatomical lung resection: a two-centre experience. Eur J Cardiothorac Surg 2018;
$54 \cdot 252-9$

17. Ng CS, Kim HK, Wong RH, Yim AP, Mok TS, Choi YH. Single-port video-assisted thoracoscopic major lung resections: experience with 150 consecutive cases. Thorac Cardiovasc Surg 2016;64:348-53.

18. Xie D, Wang H, Fei K, Chen C, Zhao D, Zhou X, et al. Single-port video-assisted thoracic surgery in 1063 cases: a single-institution experience. Eur J Cardiothorac Surg 2016;49 Suppl 1:i31-6.

19. Dindo D, Demartines N, Clavien PA. Classification of surgical complications: a new proposal with evaluation in a cohort of 6336 patients and results of a survey. Ann Surg 2004;240:205-13.

20. Sihoe AD. Reasons not to perform uniportal VATS lobectomy. J Thorac Dis 2016;8(Suppl 3):S333-43.

21. Ludwig MS, Goodman M, Miller DL, Johnstone PA. Postoperative survival and the number of lymph nodes sampled during resection of node-negative non-small cell lung cancer. Chest 2005;128:1545-50.

22. Varlotto JM, Recht A, Nikolov M, Flickinger JC, Decamp MM. Extent of lymphadenectomy and outcome for patients with stage I nonsmall cell lung cancer. Cancer 2009; 115:851-8.

23. Osarogiagbon RU, Decker PA, Ballman K, Wigle D, Allen MS, Darling GE. Survival implications of variation in the thoroughness of pathologic lymph node examination in American College of Surgeons Oncology Group Z0030 (Alliance). Ann Thorac Surg 2016;102:363-9.

24. Ou SH, Zell JA. Prognostic significance of the number of lymph nodes removed at lobectomy in stage IA nonsmall cell lung cancer. J Thorac Oncol 2008;3:880-6.

25. Boffa DJ, Kosinski AS, Paul S, Mitchell JD, Onaitis M. Lymph node evaluation by open or video-assisted approaches in 11,500 anatomic lung cancer resections. Ann Thorac Surg 2012;94:347-53.

26. Medbery RL, Gillespie TW, Liu Y, Nickleach DC, Lipscomb J, Sancheti MS, et al. Nodal upstaging is more common with thoracotomy than with VATS during lobectomy for early-stage lung cancer: an analysis from the national cancer data base. J Thorac Oncol 2016;11:222-33.

27. Licht PB, Jorgensen OD, Ladegaard L, Jakobsen E. A national study of nodal upstaging after thoracoscopic versus open lobectomy for clinical stage I lung cancer. Ann Thorac Surg 2013;96:943-9. 